DOI: http://doi.org/10.21698/simi.2018.fp41

\title{
COMPARATIVE STUDY REGARDING THE ANALYSIS OF THE METALS CONTENTS FROM BIOMASS WASTES THROUGH DIFFERENT METHODS OF DIGESTION
}

\author{
Gina Alina Traistaru (Catrina) ${ }^{1}$, Agnes Serbanescu ${ }^{1}$, Mona Barbu ${ }^{1}$, Ileana Nicolescu ${ }^{1}$, Nicolae \\ Ionut Cristea $^{1}$, Bogdan Stanescu ${ }^{1}$, Ileana Cristina Covaliu ${ }^{2}$ \\ ${ }^{1}$ National Research and Development Institute for Industrial Ecology - ECOIND, 71-73 \\ Drumul Podu Dambovitei, district 6, 060652 Bucharest, evmt@incdecoind.ro, Romania \\ ${ }^{2}$ University Politehnica of Bucharest, Faculty of Biotechnical Systems Engineering, 313 \\ Splaiul Independentei Street, Bucharest, cristina_covaliu@yahoo.com, Romania
}

\begin{abstract}
The paper presents the characterization of the content of metals from three different waste biomass using ICP-MS and AAS techniques. The purpose of the study was to finding an appropriate method of analysis for the complex matrix of waste biomass by comparing two methods of digestion using a closed system (microwave) and an open system (sand bath).

For this study were analyzed six metals ( $\mathrm{Al}, \mathrm{Mg}, \mathrm{K}, \mathrm{Ca}, \mathrm{Na}, \mathrm{Fe}$ ) in three different waste samples from agriculture, forestry and related industries (horticultural and wine waste).

It was observed that the highest concentrations of metals were recorded for the sample P3 horticultural and wine waste through both analysis techniques.

The results obtained were compared with a certified reference material (CRM) and value to demonstrate the precision of the method and the quality of the results.

The concentration obtained for $\mathrm{Al}, \mathrm{Mg}, \mathrm{K}, \mathrm{Ca}, \mathrm{Na}$ and $\mathrm{Fe}$ by microwave digestion in a closed system analyzed using ICP-MS technique were better than the AAS technique. The method of analysis chosen in this study was emphasized as being optimal for the analysis of biomass waste using performance parameters: precision, accuracy, detection limit, quantification limit and extended uncertainty.

From the obtained results it can be said that the method of digestion by using microwave systems of the metals`analysis from biomass waste is within the desired purpose.
\end{abstract}

Keywords: AAS, biomass waste, ICP-MS, major elements, solid biofuels

\section{Introduction}

Sustainable management of solid waste is a priority for all the countries. A significant increase in municipal solid waste and beyond is one of the main environmental problems in all developed countries and developing countries (Chen et al 2018). The waste composition is very important in terms of management as waste must be collected, transported, exploited and eliminated separately (Arama \& Kim 2016). Classification of waste in a category of waste: inert, non-dangerous and dangerous waste is depending on its composition (Guta et al 2017).

According to the European legislation, preventing the waste generation and performing an adequate management (recovery/disposal) is a strategy focusing on 


\section{INTERNATIONAL SYMPOSIUM "THE ENVIRONMENT AND THE INDUSTRY", SIMI 2018, PROCEEDINGS BOOK}

the prioritization of practical actions taking into account the sustainable development principles (Arama \& Kim 2016). The term "waste” means any solid, liquid or contained gaseous material that is discharged by being disposed of, burned, incinerated or recycled (Puiu \& Cruceru 2016). Biomass fuels usually contain high levels of alkali/alkaline metals, in particular potassium, and high chlorine content, as well as low sulphur concentrations, which make the deposition of corrosive ash in biomass-fired boilers a more severe issue than that in traditional coal-fired boilers (Lalak et al 2016). Biomass is the biodegradable fraction of agricultural residues (of plant and animal), forestry residues and co-products of wood, residues from related industrial sectors and products energy crops (Grigore 2016). Biomass ensure energy, construction materials, paper, fabrics, medicines and chemicals. Currently biomass fuel is used both for room heating and electricity production (Grigore 2016). By determining the metal content of a waste biomass the amount of ash resulting in a power plant after the combustion process can be estimated. The amount of ash may influence the wear of a combustion plant. In literature there are presented a number of methods of preparing samples of waste, in order to determine the heavy metals in them, such as digestion in open systems and closed systems (microwave), combustion, extraction with ultrasound and solvents dilution (Kim et al 2017).

This study shows two experimental models of characterization and analysis of content of the major elements ( $\mathrm{Al}, \mathrm{Mg}, \mathrm{K}, \mathrm{Ca}, \mathrm{Na}$ and $\mathrm{Fe}$ ) from the biomass waste. We have used two metal analysis techniques such atomic absorption spectrometry (AAS) and inductively coupled plasma mass spectrometry (ICP-MS). The best method of analysis was emphasized with performance parameters.

\section{Materials and Methods}

All the chemicals were of analytical reagent grade (Merck quality).

To examine the optimal method, a Soy Bean Meal B2271 certified reference material was used. To determine the calibration plot of the metals content was used a standardization method (EN ISO 16967: 2015).

For the mineralization of waste samples in a closed system (microwave) was used a Milestone Up Ethos equipment.

The metal concentrations were determined in comparison with the techniques: mass spectrometer with inductively coupled plasma (ICP-MS) and atomic absorption spectrometer (AAS). For the ICP-MS analysis was used a Bruker Aurora M90 equipment and for the AAS analysis was used a Perkin Elmer Pin AAcle 900T equipment.

To accomplish the study were selected three types of biomass waste coming from agriculture (P1), forestry (P2) and related industry (waste horticultural and wine) (P3). To determine the metals content of the three samples were used two methods of digestion for the decomposition of organic matter.

To verify the performance parameters was selected the waste from industries related P3 sample due to high content of metals in this sample than the other two samples. The performance parameters of the study were: the precision, accuracy, quantification limit, detection limit and extended uncertainty for the P3 sample of the six metals. The waste biomass was dried and crushed under $1 \mathrm{~mm}$.

In method I, the samples were digested in microwave system (closed system): 0,25 $\mathrm{g}$ of sample was weighed and was added to $2 \mathrm{~mL} \mathrm{H}_{2} \mathrm{O}_{2}$ and $8 \mathrm{~mL}$ of $\mathrm{HNO}_{3}$. The samples were introduced into the digester for digestion at $180^{\circ} \mathrm{C}$ for 15 minutes 


\section{INTERNATIONAL SYMPOSIUM "THE ENVIRONMENT AND THE INDUSTRY", SIMI 2018, PROCEEDINGS BOOK}

under method I. Digestion parameters used were those of the cook book of the digester equipment.

In method II, the samples were digested in a sand bath: $8 \mathrm{ml}$ of $\mathrm{HNO}_{3}$ and $1 \mathrm{~g}$ of sample with $2 \mathrm{ml}$ of $\mathrm{H}_{2} \mathrm{O}_{2}$ for 90 minutes at $120^{\circ} \mathrm{C}$.

Determination of metals from biomass samples was performed by inductively coupled plasma mass spectrometry (ICP-MS) in concentrations range from 10-50 $\mu \mathrm{g} / \mathrm{L}$ and by atomic absorption spectrometry (AAS) in the range of concentrations from 0,1 to $0,5 \mathrm{mg} / \mathrm{L}$. The results were reported in $\mathrm{mg} / \mathrm{kg}$.

For each sample were performed three folds and the obtained concentration was the average of three determinations.

\section{Results and Discussion}

\section{Performance parameters}

There were performed ten determinations for the repeatability and precision, quantification limit, detection limit and extended uncertainty for each metal concentrations in part to the $10-50 \mu \mathrm{g} / \mathrm{L}$ and $0,1-0,5 \mathrm{mg} / \mathrm{L}$ for the sample (P3) from related industries.

The results of the performance parameter in the case P3 sample (related industries) are shown in tables 1 and 2.

Table 1. Performance parameters for the P3 sample by ICP-MS technique

\begin{tabular}{c|ccccc}
\hline $\begin{array}{c}\text { Major } \\
\text { elements }\end{array}$ & $\begin{array}{c}\text { Precison } \\
\text { (mg/kg) }\end{array}$ & $\begin{array}{c}\text { Accuracy } \\
\text { (mg/kg) }\end{array}$ & $\begin{array}{c}\text { Detection } \\
\text { limit } \\
\mathbf{( m g / K g )}\end{array}$ & $\begin{array}{c}\text { Quantification } \\
\text { limit (mg/kg) }\end{array}$ & $\begin{array}{c}\text { Extended } \\
\text { uncertainty } \\
\mathbf{( \% )}\end{array}$ \\
\hline $\mathrm{Al}$ & 0.29 & 1.29 & 0.88 & 2.92 & 12.40 \\
$\mathrm{Mg}$ & 0.29 & 1.37 & 0.87 & 2.90 & 12.51 \\
$\mathrm{Ca}$ & 0.24 & 1.20 & 0.73 & 2.44 & 10.18 \\
$\mathrm{~K}$ & 0.30 & 1.84 & 0.91 & 3.03 & 14.53 \\
$\mathrm{Na}$ & 0.30 & 1.22 & 0.93 & 2.10 & 12.97 \\
$\mathrm{Fe}$ & 0.30 & 1.34 & 0.91 & 3.04 & 13.07 \\
\hline
\end{tabular}

Table 2. Performance parameters for the P3 sample by AAS technique

\begin{tabular}{c|ccccc}
\hline $\begin{array}{c}\text { Major } \\
\text { elements }\end{array}$ & $\begin{array}{c}\text { Precison } \\
\text { (mg/kg) }\end{array}$ & $\begin{array}{c}\text { Accuracy } \\
\mathbf{( m g / k g )}\end{array}$ & $\begin{array}{c}\text { Detection } \\
\text { limit } \\
\mathbf{( m g / K g})\end{array}$ & $\begin{array}{c}\text { Quantification } \\
\text { limit (mg/kg) }\end{array}$ & $\begin{array}{c}\text { Extended } \\
\text { uncertainty } \\
\mathbf{( \% )}\end{array}$ \\
\hline $\mathrm{Al}$ & 1.45 & 3.51 & 4.34 & 14.47 & 16.55 \\
$\mathrm{Mg}$ & 1.58 & 4.27 & 4.73 & 15.75 & 18.84 \\
$\mathrm{Ca}$ & 1.63 & 4.52 & 4.90 & 16.32 & 19.81 \\
$\mathrm{~K}$ & 1.61 & 3.77 & 4.82 & 16.07 & 18.66 \\
$\mathrm{Na}$ & 1.77 & 4.05 & 5.31 & 17.71 & 20.90 \\
$\mathrm{Fe}$ & 1.71 & 3.60 & 5.13 & 17.08 & 19.65 \\
\hline
\end{tabular}

The results in Table 1 and Table 2 show that the detection and quantification limits present the lowest limits for the ICP-MS technique compared to AAS technique. ICP-MS technique shows a high sensitivity for complex matrices of biomass wastes. It can be concluded that the performance parameters studied in this work fit the intended purpose only for the ICP-MS technique.

Method I of digestion

The results obtained by the method I for the three-biomass waste samples are shown in Figures 1 and 2. 


\section{INTERNATIONAL SYMPOSIUM "THE ENVIRONMENT AND THE INDUSTRY", SIMI 2018, PROCEEDINGS BOOK}

In method I, the digestion of samples were conducted in a closed system in a digester equipment at a temperature of $180^{\circ} \mathrm{C}$. The $\mathrm{P} 3$ waste sample is a complex matrix composed of a mixture of grape seed, grape vine shoots, leaves and fruit of the trees. Since the matrix is very complex, hydrogen peroxide was introduced in the digestion step to remove chlorine and sulphur from the waste biomass composition. By eliminating the interference, we managed to obtain better results using ICP-MS technique.

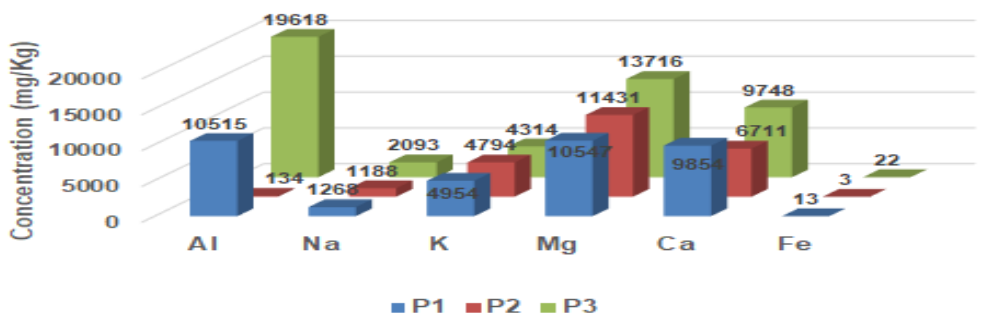

Figure 1. The results obtained from method I digestion using ICP-MS technique for the three waste samples

In figure 1 it is observed that aluminium is the predominant component in samples P1 and P3 (horticultural waste and wine), followed by magnesium, calcium, potassium, sodium and iron. Iron is present in very small quantities in all three samples (Figure 1). In P2 sample the predominant component is the magnesium concentration followed by calcium, potassium, sodium, aluminium and iron. The highest concentrations of metals were determinated for P3 sample, from horticultural and wine waste (Figure 1).

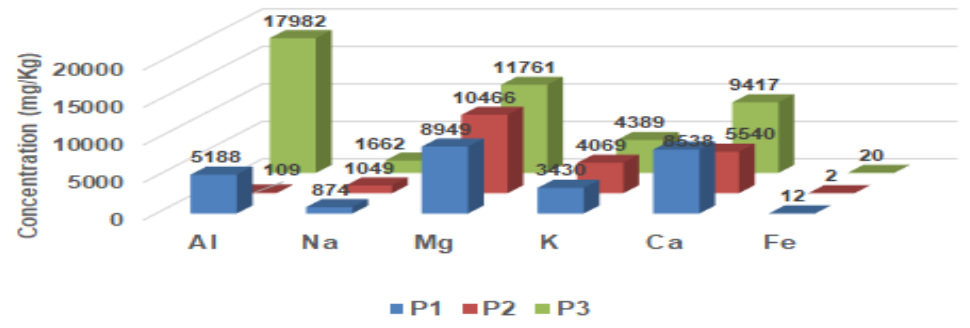

Figure 2. The results obtained from method I digestion using AAS technique for the three waste samples

In Figure 2 it was observed that the P3 biomass waste sample shows higher content of metals compared to the other two samples of waste by the microwave digestion in closed systems (method I). In P3 waste sample the major component is aluminum followed by magnesium, calcium, potassium, sodium and iron. The decreasing order of metals content for the $\mathrm{P} 1$ sample is: $\mathrm{Mg}>\mathrm{Al}>\mathrm{Ca}>\mathrm{K}>\mathrm{Na}>\mathrm{Fe}$. 


\section{INTERNATIONAL SYMPOSIUM "THE ENVIRONMENT AND THE INDUSTRY", SIMI 2018, PROCEEDINGS BOOK}

For the P2 sample the decreasing order of metals content is: $\mathrm{Mg}>\mathrm{Ca}>\mathrm{K}>\mathrm{Na}>\mathrm{Al}>\mathrm{Fe}$ (Figure 2).

Method II of digestion

In method II of mineralization were recorded lower values of metals concentrations compared to method I, for all the samples. The reason of these results is the technique of digestion (in an open system on a sand bath) (Figure 3 and Figure 4).

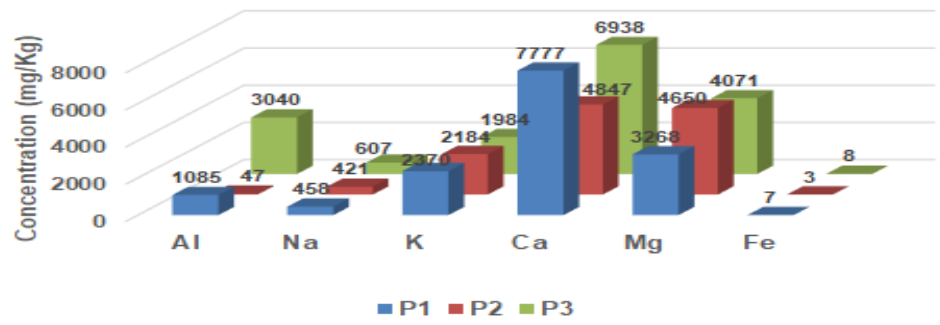

Figure 3. The results obtained from method II digestion using ICP-MS technique for the three waste samples

The major element for the P3 sample was calcium, followed by magnesium, aluminum, potassium, sodium and iron.

As in method I, the iron shows the smallest concentrations in all three samples. In $\mathrm{P} 2$ sample the decreasing order of metals content is: $\mathrm{Mg}>\mathrm{K}>\mathrm{Ca}>\mathrm{Na}>\mathrm{Al}>\mathrm{Fe}$ (Figure 3). In $\mathrm{P} 1$ sample the decreasing order of metals content is: $\mathrm{Ca}>\mathrm{Mg}>\mathrm{K}>\mathrm{Al}>\mathrm{Na}>\mathrm{Fe}$.

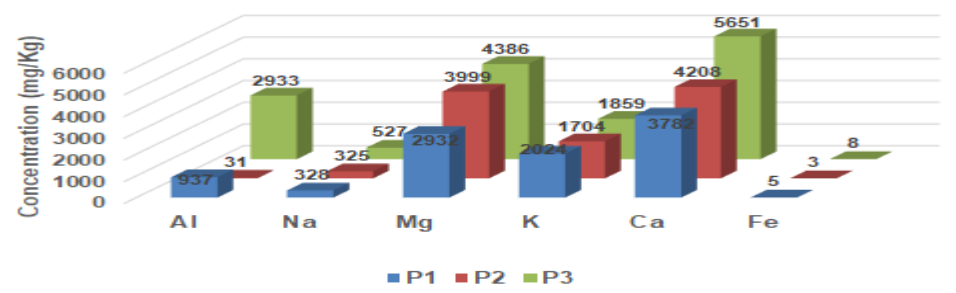

Figure 4. The results obtained by method II digestion using AAS technique for the three waste samples

The P3 sample presented high concentrations in all six metal elements. In P3 sample the predominant component is calcium, followed by magnesium, aluminum, potassium, sodium and iron. In P1 and P2 samples the decreasing order of metals content are: $\mathrm{Ca}>\mathrm{Mg}>\mathrm{K}>\mathrm{Al}>\mathrm{Na}>\mathrm{Fe}$ (Figure 4 ).

By comparing the two analysis techniques (ICP-MS and AAS) it was observed that the highest concentrations of metals presents the P3 sample using the ICP-MS techniques. It was recorded the smallest concentrations of iron with both analysis techniques for all the samples. 


\section{INTERNATIONAL SYMPOSIUM "THE ENVIRONMENT AND THE INDUSTRY", SIMI 2018, PROCEEDINGS BOOK}

The method of mineralization in an open system recorded lower values for all metal concentrations of the three waste samples compared to the mineralization in a closed system (microwave).

Results obtained for the MRC

Besides performance parameters studied in this paper, the obtained results were compared with a certified reference material with the certificated values. Results for the MRC obtained in the laboratory were reported in percentages to compare the results with the analysis certificated for Soy Bean Meal B2271.

The results obtained for the MRC are presented in the Table 3.

Tabel 3. The results obtained for the MRC by ICP-MS and AAS

\begin{tabular}{c|c|ccc}
\hline $\begin{array}{c}\text { Technical } \\
\text { analysis }\end{array}$ & $\begin{array}{c}\text { Analyzed } \\
\text { element }\end{array}$ & $\begin{array}{c}\text { MRC certificate } \\
\text { (\%) }\end{array}$ & $\begin{array}{c}\text { MRC obtained in } \\
\text { the laboratory } \\
\text { (method I) (\%) }\end{array}$ & $\begin{array}{c}\text { MRC obtained in } \\
\text { the laboratory } \\
\text { (method II) (\%) }\end{array}$ \\
\hline & Al & $\mathbf{0 . 0 1 1 1} \pm 0.0004$ & $\mathbf{0 . 0 1 0} \pm 0.0012$ & $\mathbf{0 . 0 0 7 0} \pm 0.0018$ \\
& Mg & $\mathbf{0 . 0 0 3 9} \pm 0.0004$ & $\mathbf{0 . 0 0 3} \pm 0.0013$ & $\mathbf{0 . 0 0 2} \pm 0.0019$ \\
& K & $\mathbf{2 . 4 7} \pm 0.22$ & $\mathbf{2 . 1 1} \pm 0.0015$ & $\mathbf{1 . 4 2} \pm 0.0021$ \\
ICP - MS & Ca & $\mathbf{0 . 3 3} \pm 0.04$ & $\mathbf{0 . 3 2} \pm 0.0010$ & $\mathbf{0 . 3 0} \pm 0.0017$ \\
& Na & $\mathbf{0 . 0 2} \pm 0.25$ & $\mathbf{0 . 0 1 9} \pm 0.0013$ & $\mathbf{0 . 0 1 7} \pm 0.0020$ \\
& Fe & $\mathbf{0 . 0 1 4 6} \pm 0.003$ & $\mathbf{0 . 0 1 4 4} \pm 0.0013$ & $\mathbf{0 . 0 1 4 0} \pm 0.0021$ \\
\hline \multirow{5}{*}{ AAS } & Al & $\mathbf{0 . 0 1 1 1} \pm 0.0004$ & $\mathbf{0 . 0 0 9 0} \pm 0.025$ & $\mathbf{0 . 0 0 4 0} \pm 0.033$ \\
& Mg & $\mathbf{0 . 0 0 3 9} \pm 0.0004$ & $\mathbf{0 . 0 0 2 0} \pm 0.0033$ & $\mathbf{0 . 0 0 1 9} \pm 0.0045$ \\
& K & $2.47 \pm 0.22$ & $\mathbf{1 . 6 6} \pm 0.0036$ & $\mathbf{1 . 0 1} \pm 0.0048$ \\
& Ca & $\mathbf{0 . 3 3} \pm 0.04$ & $\mathbf{0 . 2 3} \pm 0.0035$ & $\mathbf{0 . 2 1} \pm 0.0042$ \\
& Na & $\mathbf{0 . 0 2 0} \pm 0.25$ & $\mathbf{0 . 0 1 3} \pm 0.34$ & $\mathbf{0 . 0 1 1} \pm 0.44$ \\
& Fe & $\mathbf{0 . 0 1 4 6} \pm 0.003$ & $\mathbf{0 . 0 1 3 0} \pm 0.0043$ & $\mathbf{0 . 0 1 0 0} \pm 0.0052$ \\
\hline
\end{tabular}

The results obtained for the MRC analyzed in the laboratory with ICP-MS were satisfactory compared to the results obtained with AAS. We have obtained good results using ICP-MS technique for the MRC compared to AAS analysis technique, because of the sensitivity analysis techniques (Table 3).

Depending on the biomass composition, metals content can vary. Using the mineralization method in a closed system (I) were obtained higher concentrations of metal for all of the three waste samples compared to the open system mineralization method (II).

\section{Conclusions}

The aim of this study was to characterize three different biomass wastes by two digestion ways and two analysis techniques and to demonstrate the quality of the results obtained in the laboratory by using a certified reference material. The metal concentrations were recorded by AAS and ICP-MS techniques.

From all results of the samples it was observed that the highest concentrations of metals showed P3 sample as compared to the other two samples. The predominant elements were aluminum, calcium and magnesium and were analyzed by ICP-MS and AAS. Iron concentrations are very low in all three samples using both methods of analysis. The most efficient way to analyze the biomass waste is by microwave digestion in a closed system and analyzing samples by ICP-MS. Interference from 


\section{INTERNATIONAL SYMPOSIUM "THE ENVIRONMENT AND THE INDUSTRY", SIMI 2018, PROCEEDINGS BOOK}

the compounds of chlorine and sulphur coming from biomass waste was removed by the addition of hydrogen peroxide in the sample mineralization step. Good and reproducible results were obtained by digestion in a closed system at a temperature of $180^{\circ} \mathrm{C}$ for 15 minutes and analysing the samples by ICP-MS technique. This method of decomposition of organic matter is fast and safe. The results obtained by microwave digestion (method I) sustained the application of this method for the characterization of the metals` content from biomass waste.

\section{Acknowledgements}

This work was carried out through the Romanian Nucleu Programme, financed by the Ministry of Research and Innovation, Project PN 18050401.

\section{References}

Arama, MG \& Kim, L 2016, 'Using waste hierarchy concept for optimizing the management of the waste disposal amount and implicitly of the possible ecological risk', International Symposium "The Environment and The Industry",SIMI 2016, National Research and Development Institute for Industrial Ecology ECOIND, Bucharest, pp. 66-72.

BN 287568, Organic Analytical Standard of Soy Bean Meal B2271, Microanalysis Element.

Chen, X, Tai, CT, Wu, L, Tsai, FS \& Srimanus, K 2018, 'Business Models for Social Innovation of Municipal Solid Waste Recycling Companies: Comparison of Two Business Cases in Thailand and Taiwan', Sustainability, vol. 10, no. 4, 1009, pp. 1-13.

Grigore, M 2016, 'Manual for the use of solid manufacturer's: Solid biofuels properties and production', Biomass and Energy, Chisinau, pp. 9.

Guta, D, Cuciureanu, A, Kim, L \& Arama, MG 2017, 'The assessment of dangerousness of waste. Case study: waste originating from drilling muds', $20^{\text {th }}$ International symposium "The Environment and The Industry", SIMI 2017 National Research and Development Institute for Industrial Ecology ECOIND, Bucharest, pp. 189-196.

Kim, L, Muresan, AM, Cuciureanu, A, Guta D, Arama, MG, Cristea, NI \& Dediu, V 2017, 'Experimental models of characterization and analysis of industrial waste', $20^{\text {th }}$ International symposium "The Environment and The Industry", SIMI 2017 National Research and Development Institute for Industrial Ecology ECOIND, Bucharest, pp. 142-150.

Lalak, J, Martyniak, D, Kasprzycka, A, Żurek, G, Moroń, W, Chmielewska, M, Wiącek, D \& Tys, J, 2016, 'Comparison of selected parameters of biomass and coal', International Agrophysisc, no. 30, pp. 475-482.

Puiu, D \& Cruceru, LV 2016, 'Guidance tool for waste analysis in an accredited laboratory', International symposium "The Environment and The Industry", SIMI 2016, National Research and Development Institute for Industrial Ecology ECOIND, Bucharest, pp. 81-88.

SR EN ISO 16967:2015, 'Determination of major elements: Al, Ca, Fe, Mg, P, K, Si, Na, Ti, Solid biofuels'. 